\title{
"deBallution" - A Prototype of Interactive Artwork Based on Cultural Heritage
}

\author{
Je-ho $\mathrm{Oh}^{1}$, So-young $\mathrm{Kim}^{2}$, Yun Tae $\mathrm{Nam}^{3}$, and Chung-kon Shi ${ }^{1(\bowtie)}$ \\ ${ }^{1}$ GSCT, KAIST, Daejeon, Republic of Korea \\ \{aomewho, chungkon\}@kaist.ac.kr \\ ${ }^{2}$ CDE, UNIST, Ulsan, Republic of Korea \\ ahyne@naver. com \\ 3 sensiLab, Monash University, Clayton, Australia \\ yun.nam@monash.edu
}

\begin{abstract}
Based on cultural heritage plays about throwing action, we made a public interactive artwork by throwing pseudo-balls, "deBallution." Audience members participated in interactive artwork not only for pleasure but also as part of their cultural heritage, maintaining and also disrupting social orders and structures. First of all, this research extracted the audience's basic activities from cultural archetypes. Then, it applied audience activities to a basic model of public interactive artwork for playing on a media façade to participating in collective performance for disruptive social structures. The interactive artwork concept is to catch audience members' throwing movements on a virtual screen and drawing various generated kaleidoscope images to predict points from the audience throwing on the screen. We made prototype "deBallution" and then exhibited it and evaluated user tests. Through evaluation results for the prototype, we revised "deBallution" artwork contents for developing artistic values and produced overall interactive artwork.
\end{abstract}

Keywords: Interactive artwork $\cdot$ Cultural heritage $\cdot$ deBallution

\section{Introduction}

\subsection{Background and Motivation}

The audience member has often been just a spectator in public art, not a participant or creator [1-3]. Digital technologies allow audience members to help build a city's scenery by their own action $[4,5]$. It is possible to change the city's landscape using audience members' activities, mediated by digital technologies through interaction. This public experience put audience members in cooperation and competition to change a city's landscape. Digital art is avant-garde, because it makes use of digital media, which prompt interactive, participatory art, which—for its part—prompts participatory democratic society [6].

Values of public artwork make public participation an "unforgettable experience," not just a private experience of artwork. These experiences could lead to direct audience action mediated by digital technologies. In the viewpoint of the audience 
participation, Claire Bishop proposed "participatory aesthetics." These aesthetics were different from Bourriaud's "Relationship Aesthetics" [7, 8]. According to Bishop, "The artist's practice, and his behavior as producer, determines the relationship that will be struck up with his work. In other words, what he produces, first and foremost, is relations between people and the world, by way of aesthetic objects." The work of art has a social and historical context, but its role is not to engage directly with society; art is disengaged, and it has its own space. Bishop asserted that the Relationship Aesthetics concept is the ideal form of audience collaboration and cooperation. Through the public interactive artwork for media façade by audience interaction, audience members actively participate in and change contents producing a landscape of the city.

The main motivation of this paper is to produce a digital interactive artwork, building on a cultural archetype. Cultural heritage directly supports public interactive artworks in audience action and in the embodiment of contents. This audience action not only involves body movements from passive observers and performers for choosing the scene; it also involves generating energy for changing social views of politics. This aesthetic values public artwork based on cultural heritage. Through the archetypes, it was possible to extract original emotion and activity from the human universal model and derive artwork's contents - narrative, visualization, sonification, and embodiment of artwork's objective [9, 10]. Audience members participated in the public artwork and saw their shadows changing due to other audience's action on video. Cultural heritage have seen use in digital games, especially narrative ones, to extract a main character's action for their features and graphic images. Cultural heritage can also support artwork to enhance the aesthetics' values through the audience's universal activity patterns. This is because audience members have situations with mythical or traditional experiences and return to the origin model of humanity through the culture heritage.

\subsection{Related Work}

Public digital artwork has been produced in various ways. These public digital artworks gave new artistic values for collaborated or competed experience to participating audience. Lozano-Hemmer Rafael has made a public interactive artwork installation based on digital technologies, "The city as interface." Lozano-Hemmer showed that an alternative interface design is possible which stimulates brief encounters as part of everyday urban life [11]. Emily et al. proposed "The VideoMob," an interactive video platform and artwork that enables strangers visiting different installation locations to interact across time and space through a computer interface that detects their presence, video-records their actions while automatically removing the video background through computer vision, and co-situates visitors as part of the same digital environment [12]. Beyer et al. proposed "The Puppeteer Display," a wide interactive banner display installed at a city sidewalk, and two long-term field studies investigated the opportunities of public displays to actively shape the audience [13]. However these artworks or research works have not used audience archetypes to make new artwork contents. Audience members just had an experience of real life, with much the same 
patterns. Audience members did not know various meanings of their own actions and so duplicated their usual actions. This was because this artwork and research did not consider human psychology and cognition - in view of objective and result from their own actions. These audience actions effected on temporarily and not expanded public experience for making new society - new rules, communities, and role of humans. Applied archetypes will create new, expanded experiences, making various layers generate audience action-beyond space and time, age and gender.

\section{Artwork Overall Design}

\subsection{Artwork Concept}

The basic artwork concept is to make new artwork form audience members' whole-body action. The audience action will influence social values, mediated by public media.

The meanings of the title "deBallution" are as follows.

First, it means a digital revolution by throwing balls, a symbolic revolution mediated by digital artwork, a change from tradition to digital technologies. Second, it means devolution by throwing balls. Devolution is the transfer of some authority or power from a central organization or government to smaller organizations or government departments. The audience here performs symbolic devolution. Audience members threw the pseudo-balls for media façade and caused symbolic digital revolution, devolution [14].

This paper chose the throwing action to make audience resistance and destruction activities for competition and antagonism, generating a new world - not passive media or society. Why did we focus on the throwing action in the artwork? The throwing action is related to disruptive aesthetics. Concerning disruptive aesthetics, our motive was "overthrowing a society." In summation, the term "overthrowing" means "beyond throwing," which regards the accomplishment of objective through the throwing activities [15]. Overhand throwing is a basic throwing action used in war, hunting, and sports. It is a direct, fast, and accurate throw by moving the hand over the shoulder. This throw is a symbol for a strong motivation to hit a target and change a target condition.

This artwork referred three throwing games that are part of different cultural heritages.

\section{(1) Greek "Hyakintos" Myth}

Throwing discus myth content is about the origin of the flower "Hyakintos" from a relationship between a god and ordinary people in terms of friendship, love, and jealousy. However, this myth told a story about the origin of throwing action sports, which in Greece involved the discus. Unlike other sports games, throwing discus is not war game. It is a pure competition game for records [16] (Fig. 1). 


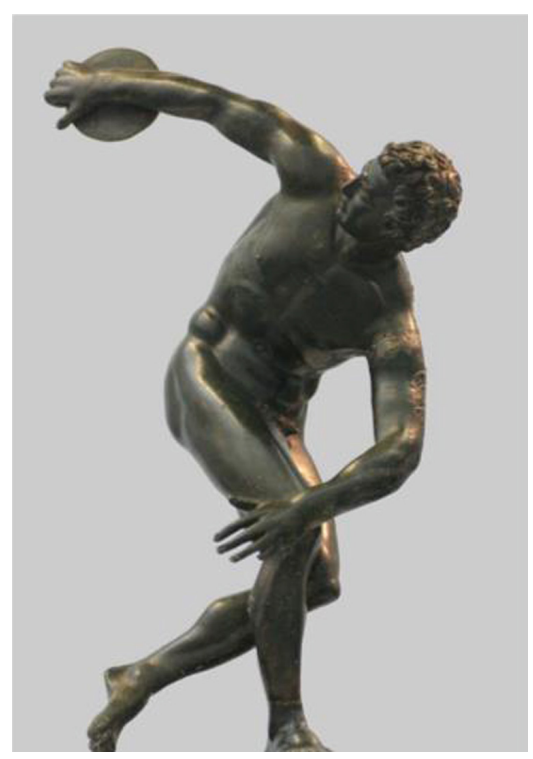

Fig. 1. Greek Hyakintos Myth [16]

(1) Main objective - Throwing a discus for a long distance single-handedly.

(2) Activities - Throwing discus with three-quarters movement, according to the rules.

(3) Values - A thrown discus will come back just like a boomerang, as will friendship and create entertainment in a group.

\section{(2) Stone War from Korean Traditional Play}

A war of throwing stones is a traditional Korean game [17]. Two communities separated and began throwing stones each other. This game came from real war but had been developed as a traditional folk game in the festival. The game enhanced a group relationship through competition in each community (Fig. 2).

(1) Main objective - Competing and winning by throwing stones for communities.

(2) Activities - Throwing real stones and avoiding or defending against stones from opponents

(3) Values - Establishing cooperation within the community and competition with opponent communities. The ultimate value was to strengthen both for future real battles.

\section{(3) Battle of the Oranges from Ivrea in Italy}

The Battle of the Oranges is a festival at Ivrea in Italy. It involves some thousands of towns people, divided into nine combat on-the-ground teams, who throw oranges at tens of card-based teams - with considerable violence - during the last three carnival 


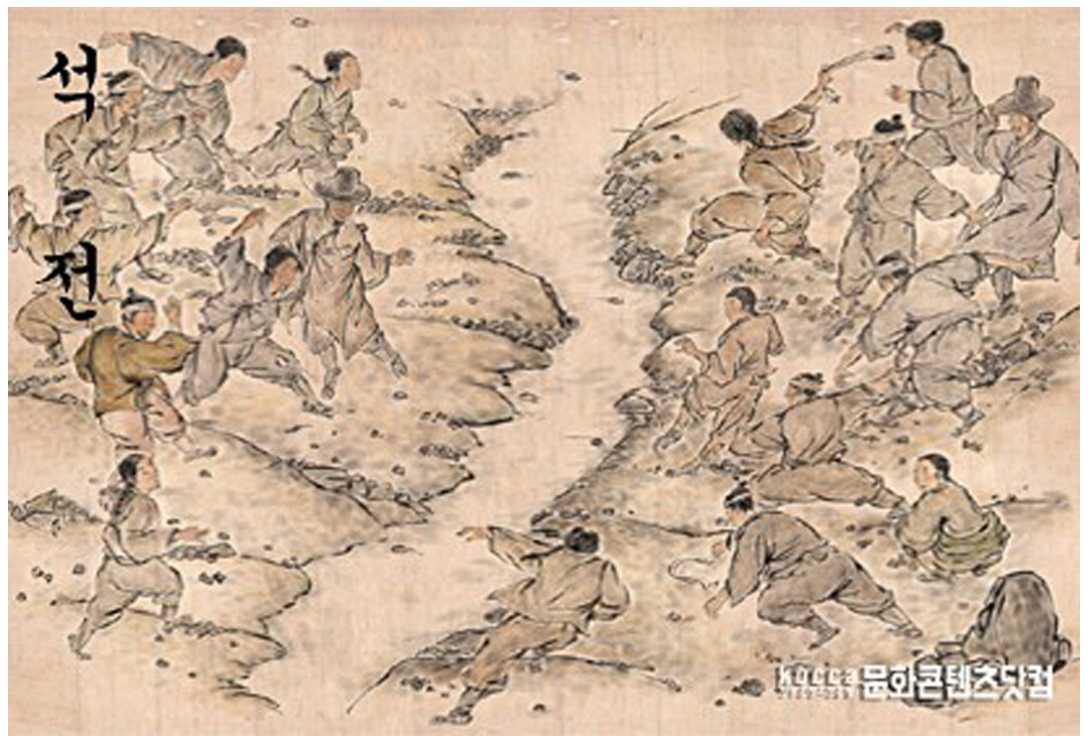

Fig. 2. War of throwing stones in Korea [17]

days [18]. People wearing a red hat will not be considered part of the revolutionaries, and therefore will not have oranges thrown at them. These traditional games were based on participators throwing. The participators enjoyed the game like they were playing at war and felt the pleasure of rebellion and victory (Fig. 3).

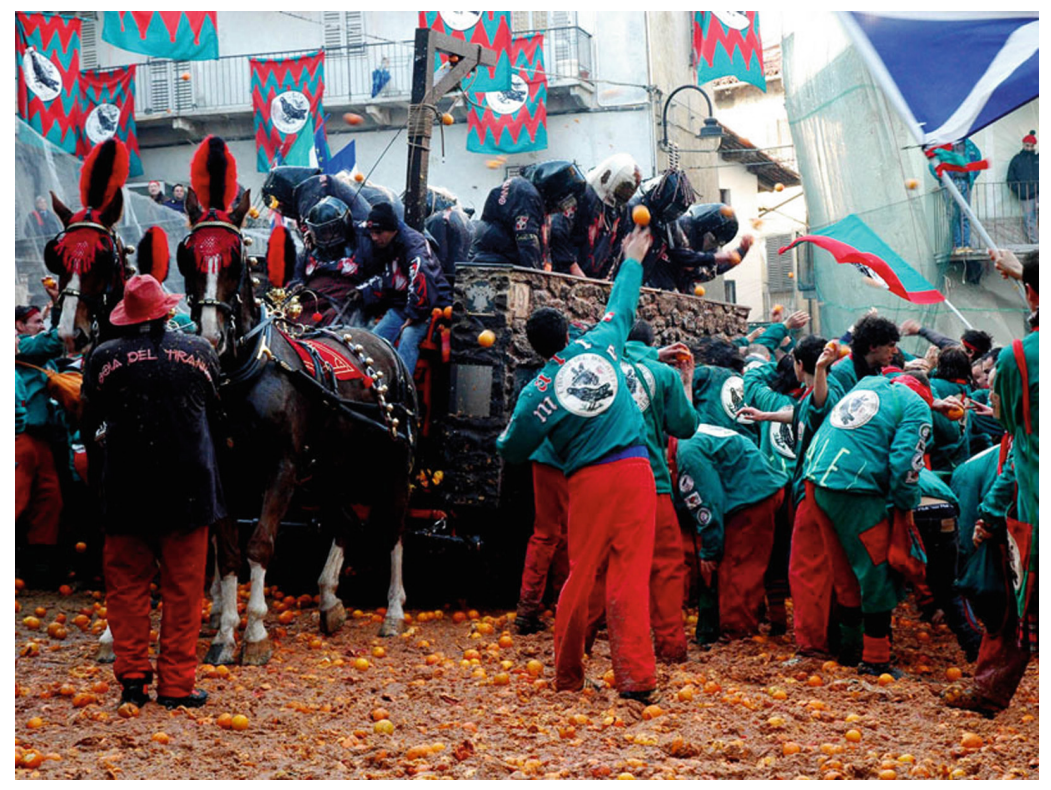

Fig. 3. Battle of the oranges in Ivrea [18] 
(1) Main objective - Throwing real oranges to opponents and win the official guards as traditional carnival.

(2) Activities - Throwing real oranges and avoid flying oranges

(3) Values - Revolution for ordinary people in carnival game and visualization pleasure by crushed oranges.

These archetypes have features for throwing action by individual or group and are beyond making festival play, making a new world.

\subsection{Scenario Design}

We created "deBallution's" scenario design based on the previous artwork concept and applied by narrative forms [19].

(1) Audience members watched video contents about city's landscape on a media façade or a large display.

(2) Audience members threw pseudo-balls onto the media façade or the large display.

(3) Video contents in the media façade or the large display broke or generated pseudo-balls.

(4) Audience members disrupted the video content when they filled the media façade or the large display with broken or generative images.

(5) The new content that played in the media façade or the large display symbolized a new world.

\subsection{Graphic Design}

The main concept of graphic design is to visualize audience throwing action to generate new images on the throwing point. The contents express visually that participants desire to overthrow reality by throwing. The first screen images are realistic and fanciless, reflecting everyday life. After participants throw, a festival starts on the screen, but the screen begins to be damaged. At any point where a participant throws, a kaleidoscope image expands just like images of crushed oranges. The throwing action has usually happened at festival in the past. The throwing action in this project means that participants gather and they set off firecrackers by making a festival. The kaleidoscope images are like firecrackers and reminiscent of festivals. The many points of the action signify the many participants. Ernest Edmund used kaleidoscope images in basic interactive research to generate various pattern images from audience action [20, 21]. These repeated throwing actions of participants creates recurring but diverse patterns of firecrackers. These lead participants into a rhythmic fireworks festival. The various images of firecrackers depend on the motion of the participants. This is intended to emphasize the diversity of individuals. After festival ends soon, strange images like errors appear on the screen. These little errors lead to big changes and damages. Finally, participants overthrow the screen image. The glitch effect is used for the damage effect, as it is similar to the principle of a glitch. Unintended simple errors by participant generate the new screen. This gives a positive meaning to errors, failure, and the participants' ultimate conquest of the screen (Fig. 4). 

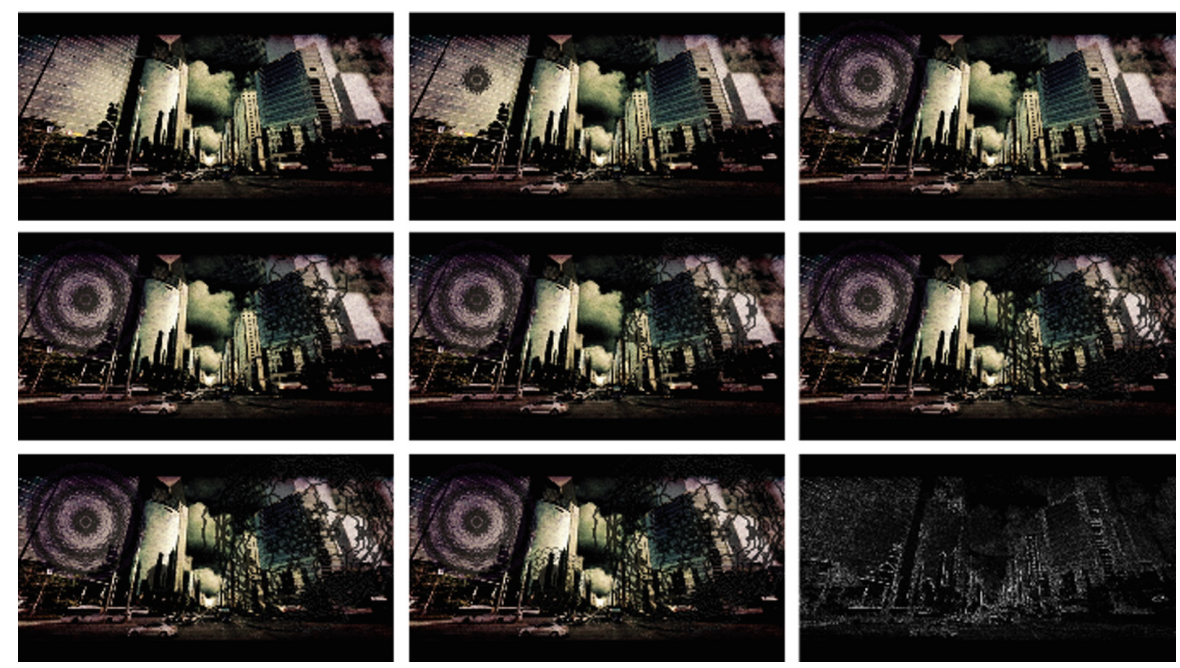

Fig. 4. Examples of graphic design [14]

\subsection{Applied by Aesthetics for Artwork}

Audience members could put their emotions in the artwork and change their emotions through participation in the artwork. This artwork is based on technical implementation and graphic design. However, these technical factors of the interactive installation would not lead to interactive artwork without aesthetic values. This project did not serve designs or technical devices, but two aesthetic values-pleasure framework and disruptive aesthetics.

\section{(1) Pleasure Framework}

The concept of pleasure framework proposes thirteen pleasures - creation, exploration, discovery, difficulty, competition, danger, captivation, sensation, sympathy, simulation, fantasy, camaraderie, and subversion by participation in an interactive artwork. These are only possible categories that a participant might feel pleasure in during an interactive art experience [22]. Audience members could experience the following emotions, typically by participating in "deBallution" through a pleasure framework.

(1) Creation - Audience members felt they were part of the creation when they drew a new painting by making a circle, making a new world through their own actions.

(2) Discovery - Audience members discovered new unfamiliar scenery of the city. Particular actions may provoke different images and transformed contents.

(3) Difficulty - Audience members had difficulty making circles on the screen precisely where they wanted to draw them. This difficulty gamified the experience, focusing them on achieving a goal.

(4) Competition - Audience members participated in "deBallution," in collaboration. They tried to achieve a defined goal together. Completing the goal 
could involve working with or against another human participant when making a new world.

(5) Subversion - Audience members could destroy the background image on the screen and create the new world through their own action.

\section{(2) Disruptive Aesthetics}

Artworks each have their own artistic values. Disruptive aesthetics placed artistic value on social meanings [23]. Especially, they lead audience members to break down traditional social values. The audience overthrows the social order and proposes a new world (Fig. 5).

(1) Audience - Audience threw pseudo-balls.

(2) Interactive installation - The installation represented a screen video and covered circle images, influenced by audience action.

(3) Artwork contents - The previous background video broke down after the audience filled it with generative circle images; a new, futuristic video ensued.

(4) Breaking a rule/community/role - Audience members disrupted the city landscape in the screen by their own activities. Such disruptive aesthetics in "deBallution" broke down the rule of maintaining community and created a new world.

These aesthetics will influence the artwork, creating a new artistic value and experience independent of design values or technical implementation issues.

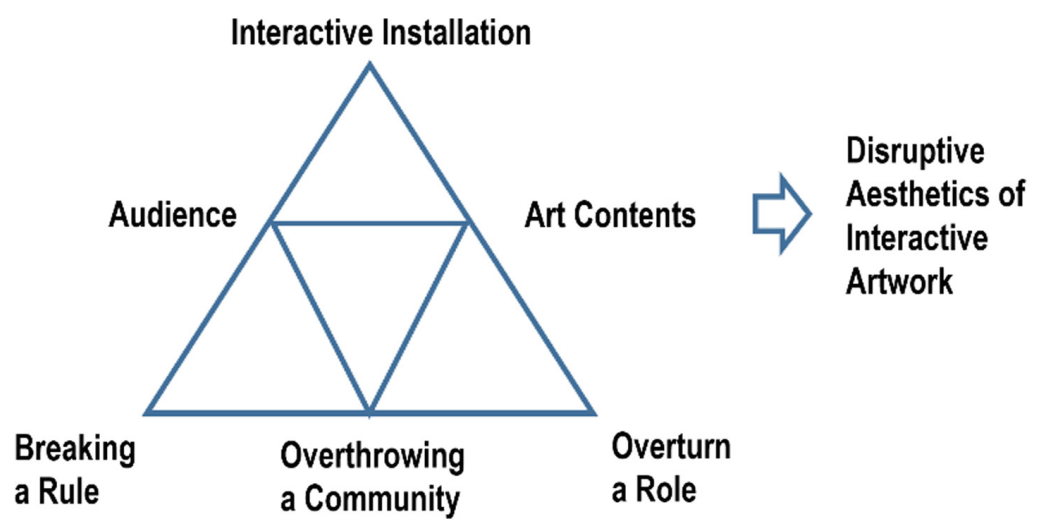

Fig. 5. Disruptive aesthetics of interactive artwork [23]

\section{Prototype and Evaluation}

\subsection{Prototype Implementation}

The prototype focused on audience throwing action and reflecting on the screen circle images. 
These audience activities could be possible to two or three participants. Those images filled the screen and disrupted background images. This distorted content is a new world the audience itself created by changing city scenery.

The prototype made by openFrameworks, used $\mathrm{C}++$ programming connected by Kinect. This is because, in the prototype test, video about scenery of the city played on a small screen instead of a media façade and focused on audience activities not on video contents. Audience members made throwing gestures in front of the screen, which generated circle images at the positions of the audience's throwing by calculating virtual location through Kinect, connected by openFrameworks programming. Audience members continued throwing and circle images at the position of the previous images and new images expanded on the screen progressively until the screen filled with images covering up the scenery of the city. At that time, the screen was full of various circle images. The origin video was a reversal of the screen and the audience's throwing play was completed.

Video cuts from prototype exhibition are as follows (Fig. 6).
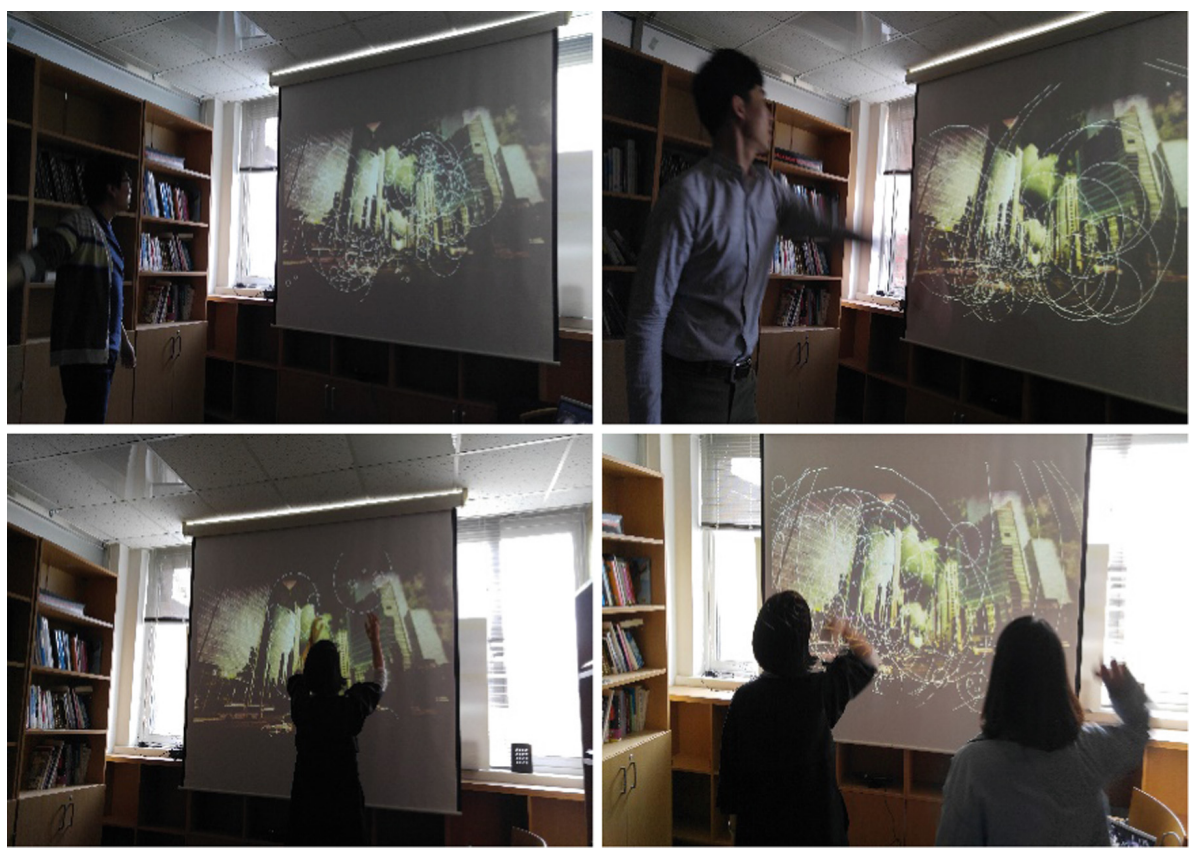

Fig. 6. Still frames of prototype "deBallution"

\subsection{Evaluation Factors}

After the prototype exhibition, we evaluated the user test and group interview.

Ten participants ( 5 males, 5 females) performed in the prototype test. Their ages ranged from 22 to 38 years old $\left(\mathrm{x}^{-}=28.2\right)$; eight were right-handed, and 2 were left-handed. 
Participants could throw pseudo balls as much as they wanted without a restriction on time or throwing numbers. After a survey, we interviewed the participants. In the participant interviews, we focused on two questions involving social group play experimentation and development ideation for increasing the artwork value.

\subsection{Results and Discussion}

\section{(1) Main objective}

The highest factor concerning the main objective of the participants was making circles in the content (Fig. 7).

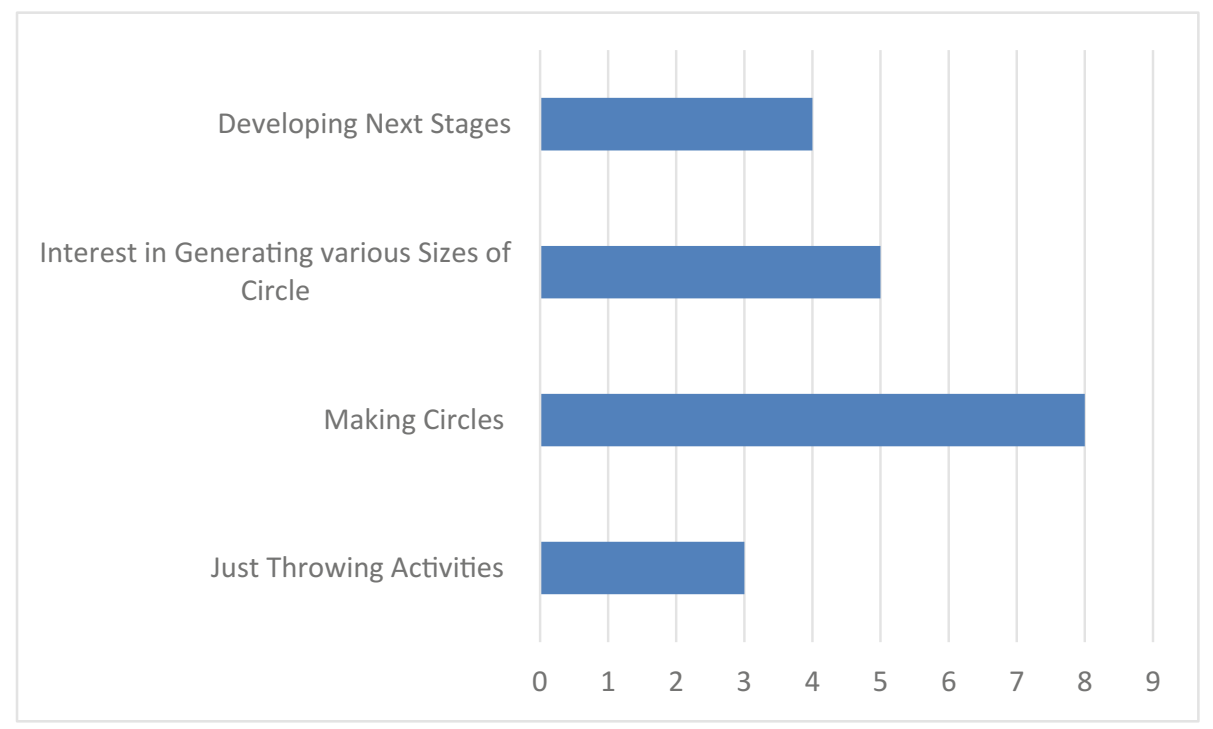

Fig. 7. Result of main objective

This means that participants wanted to know the results of their own activities, and just the throwing action would be possible to influence content. Participants were interested in the throwing action for making circles and developing next stages. The participants' objectives influenced content development because they wanted to change the media through interaction. This objective is different in regards to observation or appreciation from Bishop's viewpoint of participatory aesthetics. However, participants had different objectives and desires. In the developing artwork, we focused on participant activities of adjusting different images by throwing actions, reflecting their own desire and creating antagonism and competition between the participant groups. 


\section{(2) Activities}

The average number of throwing actions was 37 . Continued throwing activities by the audience meant that the participants were immersed in the "deBallution", because the test did not ask how many throwing activities were performed.

Participants performed voluntary throwing actions in the prototype test. This was because participants wanted to watch the "deBallution" content of their own actions and were interested in participation by making circles. Then, participants acted on the artwork with various throwing actions and poses, just like game play. For example, participants jumped for power-up throwing, shot-put throwing, and throwing with both hands. The original throw for this artwork was the overhand throw, which means "overthrowing the rule, community, and role," by participants; however, participants made various throwing actions: side-arm, underhand, three-quarters, twisted throwing, and jump throwing. Trials of a throwing action with a whole body movement especially influenced audience emotion through participation. This result means that the audience wanted to act on various self-objectives and were not controlled by installation limitations. This is because the "deBallution" installation fit the audience overhand throwing action; however, it could be perceived with other throwing actions as well. Participants preferred group play over single play. This means that participants wanted to play in collaboration, competition, or conflict for self-motivation.

\section{(3) Values}

Participants had various artistic values in the prototype of "deBallution."

The highest factor of the pleasure framework was the creation pleasure. Subversion and simulation were the second highest factors in this framework (Figs. 8 and 9).

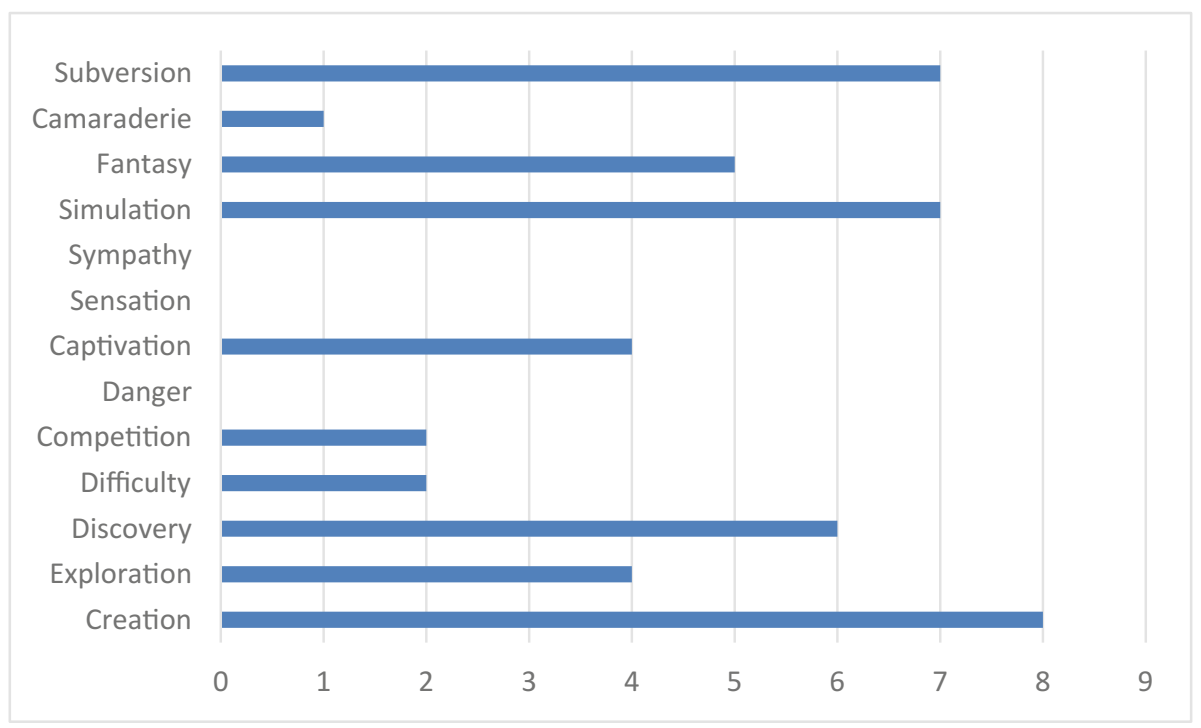

Fig. 8. Result of pleasure framework 


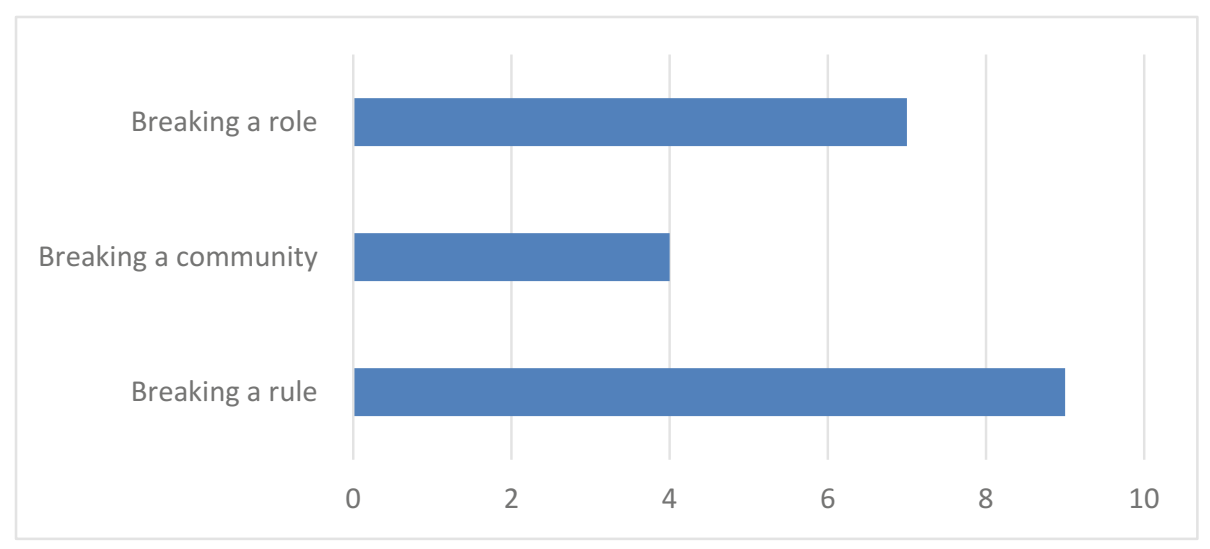

Fig. 9. Result of disruptive aesthetics

The highest factor of disruptive aesthetics was the overthrowing rules. The highest factor of content developing the artwork was the circle image changing to other images.

Narrative development, background image modifying, and competition among participants were the highest factors in the developing elements. In the interview, participants proposed various background images and videos. The participants also wanted to perform by stage level, developing like storytelling or gamification. In general, participants' interests and immersion were increased by group performance. This is because competition influenced participants' throwing objectives and enhanced their throwing action skills. In short, participants wanted to experience dramatic visualization by their own activities and changing of artwork values. These elements were our intended objective.

We found the pleasure framework and disruptive aesthetics in the artwork. The interactive artwork outcome generated intended or unintended audience participation [24]. Participants were absorbed with the "deBallution" merely by the throwing activities. Participants drew their own images of their own throwing actions. They wanted to draw circle images where they drew-just like the abstract drawings of Kandinsky or Jackson Pollock. Participants wanted to draw the same size and location image as the previous throwing points due to their reflection desire. This means that they wanted to draw an in-depth layered visualization of the circle image and background. Participants had a duplication desire for their own creatures and developed the next stages. These participant-desired actions will adjust the realization of public interactive artwork "deBallution." They will generate more active unintended actions and create a new image relation between the background image and the participants generating images. These artwork values were values of participatory artwork by Claire Bishop, influencing a new world by direct participant activities [7]. These results mean that the throwing action autonomously influenced various participant activities. Using these activities, it was possible to make developing contents and artistic values. In the prototype test, audience members threw imaginary objects and generated extended circle images. Those images filled the screen and disrupted background images. This distorted content is a new world the audience itself created by changing city scenery. 


\section{Realization of Artwork}

\subsection{Revised Contents}

The original objective for the "deBallution" was seeing a display for a media façade or a large display. Through the discussion, we revised the contents with the prototype test results. The follow table is a summary of the changing contents in the artwork (Table 1).

Table 1. Summary of the changing contents in the artwork

\begin{tabular}{l|l|l}
\hline Factors & Prototype & Realization "deBallution" \\
\hline $\begin{array}{l}\text { 1. Background } \\
\text { image }\end{array}$ & Fixed scene of GangNam street in Seoul & $\begin{array}{l}\text { The Opera House in Sydney - } \\
\text { Changing color and image }\end{array}$ \\
\hline $\begin{array}{l}\text { 2. Audience } \\
\text { throwing action }\end{array}$ & $\begin{array}{l}\text { Audience throwing generated various } \\
\text { circles in the screen in terms of location } \\
\text { and speed }\end{array}$ & $\begin{array}{l}\text { Audience throwing generated } \\
\text { various kaleidoscope points on } \\
\text { the screen in terms of location } \\
\text { and speed }\end{array}$ \\
\hline $\begin{array}{l}\text { 3. Visualization } \\
\text { for throwing } \\
\text { action }\end{array}$ & Just visualized circle, but size varied & $\begin{array}{l}\text { Circle changed to kaleidoscope } \\
\text { images, and the kaleidoscope } \\
\text { images expanded }\end{array}$ \\
\hline $\begin{array}{l}\text { 4. Climax scene } \\
\text { Background image changed to } \\
\text { various color tones and blurred } \\
\text { outlines }\end{array}$ \\
\hline 5. Ending scene & N/A & $\begin{array}{l}\text { Background image changed to } \\
\text { cultural heritage image }\end{array}$ \\
\hline
\end{tabular}

For increased audience participation, we applied these audience action patterns in the prototype to generate random kaleidoscope images.

\subsection{Realization "deBallution"}

The system was designed to recognize the users' throwing actions and patterns. The 6 main parameters included the elbow's $\mathrm{x}, \mathrm{y}$, and $\mathrm{z}$ positions and the hand's $\mathrm{x}, \mathrm{y}$, and $\mathrm{z}$ positions. These were observed and analyzed to make a decision as to whether or not throwing actions happened. The patterns of the audience's throwing experiences were used to describe interactivity in levels (low, medium, high). The "high" level of interactivity concerns a meaningful interaction between the system and the participants. The audiences become active authors or creators. The diversity of interactivity levels comes in different shapes, sizes, and colors of 3D generative kaleidoscopes. For instance, high-level interactions make bigger sizes, dynamic shape changes in animation, and vibrant shades of red. Based on color theory, this is associated with different meanings: energy, strength, power, and celebration. "Medium" levels of interaction are possible to make a middle range of sizes, animation, and comfort shades of green that create feelings of relaxation, balance, and soothing emotions. "Low" 

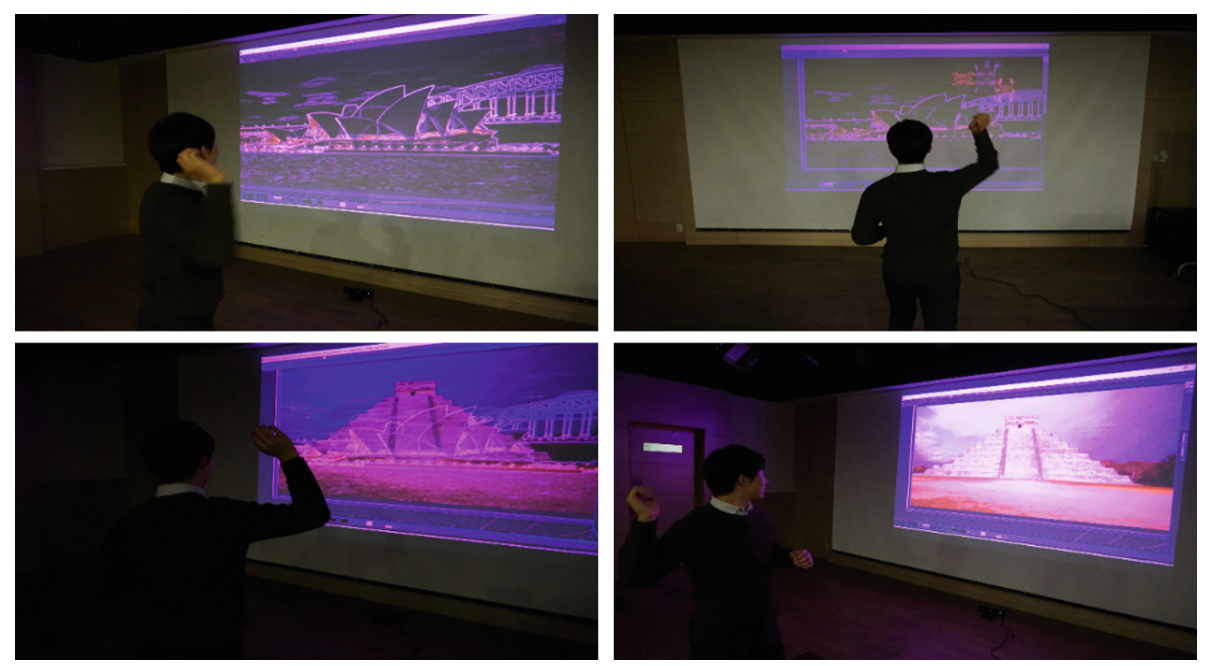

Fig. 10. Exhibition of "deBallution" (Color figure online)

levels of interaction create small sizes, changes, and sophisticated shades of blue that are associated with emotions of calmness, spirituality, and futurism [14] (Fig. 10).

\subsection{Conclusion}

In this paper, we proposed the basic prototype of interactive artwork "deBallution" based on cultural heritages. Audience members threw pseudo balls on a screen and could make a new world by their own activities in the interactive artwork based on cultural heritage.

\section{References}

1. Hu, J., Funk, M., Zhang, Y., Wang, F.: Designing interactive public art installations: new material therefore new challenges. In: Pisan, Y., Sgouros, N.M., Marsh, T. (eds.) ICEC 2014. LNCS, vol. 8770, pp. 199-206. Springer, Heidelberg (2014). doi:10.1007/978-3-66245212-7_25

2. Narumi, T., Yabe, H., Yoshida, S., Tanikawa, T., Hirose, M.: Encouraging people to interact with interactive systems in public spaces by managing lines of participants. In: Yamamoto, S. (ed.) HIMI 2016. LNCS, vol. 9735, pp. 290-299. Springer, Cham (2016). doi:10.1007/ 978-3-319-40397-7_28

3. Zhang, Y., Frens, J., Funk, M., Hu, J., Rauterberg, M.: Scripting interactive art installations in public spaces. In: Kurosu, M. (ed.) HCI 2014. LNCS, vol. 8510, pp. 157-166. Springer, Cham (2014). doi:10.1007/978-3-319-07233-3_15

4. Bullot, N.J.: The functions of environmental art. Leonardo (2014)

5. Liang, F., et al.: Information-based development trend of building skin design. Leonardo 47 (2), 173-175 (2014) 
6. Best-Dunkley, A., Puustinen, M.: RE/F/r. ACE: a participatory media artwork. Digit. Creativity 23(2), 136-143 (2012)

7. Bishop, C.: Antagonism and Relational Aesthetics. MIT Press, Cambridge (2006)

8. Bishop, C.: Contingent Factors: A Response to Claire Bishop's Antagonism and Relational Aesthetics'-Response, vol. 115, p. 107, October 2006

9. She, J., et al.: Drag a star: the social media in outer space. In: Proceedings of the 23rd Annual ACM Conference on Multimedia Conference. ACM (2015)

10. Kriss, R.-B.: Shadowed by images: Rafael Lozano-Hemmer and the art of surveillance. Representations 111(1), 121-143 (2010)

11. de Waal, B.G.M.: The city as interface. Digital Media and the Urban Public Sphere (2012)

12. Emily, G., et al.: The VideoMob interactive art installation connecting strangers through inclusive digital crowds. ACM Trans. Interactive Intell. Syst. 5(2), 7 (2015)

13. Beyer, G., et al.: The puppeteer display: attracting and actively shaping the audience with an interactive public banner display. In: Proceedings of the 2014 Conference on Designing Interactive Systems. ACM (2014)

14. Oh, J.-H., Kim, S.-Y., Nam, Y.T., Shi, C.-K.: deBallution -interactive artwork by throwing pseudo balls based on cultural heritages. In: Proceedings of the 2016 IEEE International Symposium on Mixed and Augmented Reality Conference (2016)

15. http://www.etymonline.com/index.php?term=overthrow\&allowed_in_frame $=0$

16. Bulfinch, T.: Bulfinch's Greek and Roman Mythology: The Age of Fable. Courier Corporation, North Chelmsford (2012)

17. http://terms.naver.com/entry.nhn?docId=1010795\&cid=50221\&categoryId=50230

18. http://www.storicocarnevaleivrea.it/la-manifestazione/glossario/glossario-b/battaglia-dellearance/

19. Oh, J.-H., et al.: A study of interactive art in the narrative form of "magic monkey". In: Proceedings of the Eighth International Conference on Computer Graphics, Imaging and Visualization, pp 39-46. IEEE (2011)

20. Costello, B., et al.: Understanding the experience of interactive art: Iamascope in Beta_space. In: Proceedings of the Second Australasian Conference on Interactive Entertainment. Creativity \& Cognition Studios Press (2005)

21. Muller, L., Edmonds, E.: Living laboratories: making and curating interactive art. In: SIGGRAPH 2006 Electronic Art and Animation Catalog, pp. 160-163 (2006)

22. Costello, B., Edmonds, E.: A study in play, pleasure and interaction design. In: Proceedings of the 2007 Conference on Designing Pleasurable Products and Interfaces, pp. 76-91. ACM (2007)

23. Oh, J.-H., Shi, C.-K.: Disruptive aesthetics for interactive artwork. In: Proceedings of the International Symposium on Electronic Art (2015)

24. Ernest, E.: The art of interaction. Digit. Creativity 21(4), 257-264 (2010) 